Original Research Paper

\title{
Parameter Settings for New Generational Genetic Algorithms for Solving Global Optimization Problems
}

\author{
Siew Mooi Lim, Md. Nasir Sulaiman, Norwati Mustapha and Abu Bakar Md. Sultan \\ Faculty of Computer Science and Information Technology, Universiti Putra Malaysia, Malaysia
}

Article history

Received: 16-06-2015

Revised: 14-09-2015

Accepted: 27-10-2015

Corresponding Author:

Siew Mooi Lim

Faculty of Computer Science

and Information Technology,

Universiti Putra Malaysia,

Malaysia

E-mail: limsm66@gmail.com

\begin{abstract}
This study operates within experimental design with two main tools of Taguchi method namely orthogonal array and signal to noise ratio to discover the optimal parameter settings for newly proposed generational genetic algorithms; they are Laplace Crossover-Scale Truncated Pareto Mutation (LX-STPM) and Rayleigh Crossover-Scale Truncated Pareto Mutation (RX-STPM). It concluded that GA parameter settings are algorithms and problems dependent.
\end{abstract}

Keywords: Genetic Algorithms, Parameter Settings, Taguchi Method

\section{Introduction}

Genetic Algorithm (GA) is one of the most prevalently used stochastic search techniques. This algorithm employs two main strategies; that is exploration and exploitation to locate the optimum solutions. Both of the GA features are regulated by the GA operators and some major GA parameters such as crossover probability $\left(\mathrm{P}_{\mathrm{c}}\right)$, mutation rate $\left(\mathrm{P}_{\mathrm{m}}\right)$ and tournament size $\left(\mathrm{T}_{\mathrm{s}}\right)$. Since $\mathrm{GA}$ parameters can be divided into several levels, there are almost infinite numbers of possibilities. All of which poses existing challenge to the current studies in GA.

We proposed ideal GA operators with appropriate parameters and mechanisms to overcome global optimization problems such as Conformational Search (CS). CS problems are extremely challenging due to the volume of the search space. Our newly proposed generational GA called RX-STPM is capable in solving two CS application problems i.e., minimizing a molecular potential energy function and finding the most stable conformation of pseudo ethane through a molecular model, which involves a realistic energy function. RX-STPM was based on a combination of the proposed Rayleigh Crossover (RX) and proposed Scale Truncated Pareto Mutation (STPM) operators. The details of RX-STPM and its applications on CS problems are reported in (Lim et al., 2014a; 2014b; Lim et al., 2015a; 2015b; 2015c).

\section{Taguchi Approach}

R.A. Fisher is the pioneer in developing experimental design methods (Montgomery, 2008). On the downside, the conventional experimental design is tedious due to the fact that the large number of experiments increases proportionally with the number of process parameters. These parameters are most likely to influence the performance of a studied system. To rectify that flaw, Genichi Taguchi presented an efficient and systematic approach called the Taguchi method to iron out the existing issues present in the conventional experimental design. Hence, our studies incorporate the Taguchi method in the proposed operators. Past studies have revealed that the experimental design of the Taguchi method has been proven to work in engineering problems and improved the operating conditions in products, processes, or equipment and many complex systems (Tsai et al., 2004; Liu and Cai, 2005). For instance, Camposeco-Negrete (2013) applied the Taguchi methodology to minimize cutting power or cutting energy. Davim (2003) applied the Taguchi techniques to investigate the cutting characteristics of MMC (A356/20/SiCp-T6) using PCD cutting tools. On top of that, Abhang and Çakıroğlu (Abhang and Hameedullah, 2012; Çakıroğlu and Acır, 2013) applied the Taguchi method in optimization of machining parameters in steel turning operation and optimization of cutting parameters on drill bit temperature in drilling respectively.

Some important applications based on the combination of GA with Taguchi methods are highlighted as follows: Taguchi-hierarchical genetic algorithm (Taguchi HGA) (Hsieh et al., 2001) was implemented to ensure the stability and optimal parameters control of both the grey predictor and the fuzzy gain scheduling controller. GA and Taguchi 
method on setting the parameters for $P_{c}, P_{m}$ and $P_{s}$ were incorporated in overcoming the economic power dispatch problem (Younes and Rahli, 2006). Last but not least, the Taguchi method was collaborated with response surface method and GA in parameters optimization was applied on a nano-particle wet milling process (Hou et al., 2007). Using the Taguchi SelfAdaptive Real-Coded Genetic Algorithm (TSARCGA), economic dispatch problem with valve-point loading was elucidated (Subbaraj et al., 2011).

De Jong (2007) conducted an extensive 30 years perspective on parameter setting in EAs and it was reported that optimal parameter setting is problem dependent. Thus far, the verdict on the optimum parameterization of GA operators is still inconclusive.

\section{Evaluation Analysis}

This section describes the process of a heavy experimental study which was conducted to determine the design factors of $P_{c}, P_{m}$ and $T_{s}$ that affect the output of the proposed RX and STPM operators. Five levels for each design factors are proposed. The values for each level are presented in Table 1 .

The two main tools of Taguchi method namely orthogonal arrays and Signal-to-Noise $(\mathrm{S} / \mathrm{N})$ ratio are conducted on the GA parameter settings. These tools are used to study all the variables in decision and to measure the quality of solutions. The orthogonal arrays represent a small number of experiments required to determine the appropriate level of each parameter to obtain an optimal solution. $\mathrm{S} / \mathrm{N}$ ratios, on the other hand, are used to analyze the experimental results in order to determine the suitable level for each parameter.

Capturing Data for Orthogonal Arrays and Signalto-Noise Ratio

The orthogonal arrays are represented as $\mathrm{L} n\left(\mathrm{~K}^{n-1}\right)$, where $\mathrm{n}=2^{m}$ is the number of experimental runs, $m$ is a positive integer, $K$ is the number of level for each parameter and $n-1$ is the number of columns in an orthogonal array chart (Subbaraj et al., 2011). For example, in a classical experimental design of three parameters-five levels, the total number of possible experiments is $5^{3}$ or 125 . However, when this requirement is presented in a $\mathrm{L}_{25}\left(5^{2}\right)$ orthogonal array chart, the optimum design reduced to a significant 25 experiments. These 25 experiments are able to locate the best solution with suitable parameter levels.

The $\mathrm{S} / \mathrm{N}$ ratio for each experiment in the orthogonal array is calculated to determine the optimal settings that design factors have on the output. The following formula shows the calculation for $\mathrm{S} / \mathrm{N}$ ratio (Fraley et al., 2006):
$\mathrm{SN}_{\mathrm{i}}=10 \log \frac{\bar{y}_{i}^{2}}{S_{i}^{2}}$

Where:

$$
\begin{gathered}
\bar{y}_{i}=\frac{1}{N_{i}} \sum_{u=1}^{N_{i}} y_{i, u} \\
S_{i}^{2}=\frac{1}{N_{i}-1} \sum_{u=1}^{N_{i}}\left(y_{i, u}-\bar{y}_{i}\right)
\end{gathered}
$$

$y_{i}=$ Mean value of the performance characteristic for a given experiment

$S_{i}=$ Variance

$i=$ Experiment number

$u=$ Trial number

$N_{i}=$ Number of trials for experiment $i$

All the ten benchmark global optimization test problems and the two CS application problems used in this study are of minimization types (Lim et al., 2014a). The following shows the definitions of $\mathrm{S} / \mathrm{N}$ ratio applied for minimizing the performance characteristic in all cases:

$\mathrm{SN}_{\mathrm{i}}=-10 \log \left(\sum_{u=1}^{N_{i}} \frac{y_{u}^{2}}{N_{i}}\right)$

\section{Results}

The results and observations obtained from the experimentations are presented. As shown in Table 1, the design factors are $P_{c}, P_{m}$ and $T_{s}$. For each combination of design factors, the mean of optimum values for all the test problems are obtained. In order to observe the performance of the proposed operators, GA is implemented directly by only focusing on the quality of the solutions produced by objective function values (each parameter set). Therefore, the orthogonal arrays are used for the arrangement of design factors. Table 2 and 6 show the average mean of optimum values obtained by LX-STPM and RX-STPM respectively for all the ten test problems according to the three parameters-five levels $\mathrm{L}_{25}\left(5^{2}\right)$ orthogonal array chart.

The performance characteristics in the analysis of the $\mathrm{S} / \mathrm{N}$ ratio have been categorized into the-lower-thebetter, the-higher-the-better and the-nominal-thebetter. The greater $\mathrm{S} / \mathrm{N}$ ratio corresponds with the smaller variance of the output characteristic around the desired value. We can thus conclude that the optimal level of the design factor is the level with the greatest $\mathrm{S} / \mathrm{N}$ ratio (Fraley et al., 2006). The outcomes of S/N ratio analysis for LX-STPM and RX-STPM are presented in Table 3-8. 
Table 1. The level of design factors used in this study

\begin{tabular}{|c|c|c|c|c|c|}
\hline \multirow[b]{2}{*}{ GA Parameter } & \multicolumn{5}{|l|}{ Level } \\
\hline & 1 & 2 & 3 & 4 & 5 \\
\hline Crossover probability $\left(\mathrm{P}_{\mathrm{c}}\right)$ & 0.600 & 0.650 & 0.700 & 0.75 & 0.80 \\
\hline Mutation $\operatorname{rate}\left(\mathrm{P}_{\mathrm{m}}\right)$ & 0.001 & 0.003 & 0.006 & 0.01 & 0.02 \\
\hline Tournament $\operatorname{size}\left(\mathrm{T}_{\mathrm{s}}\right)$ & 2.000 & 3.000 & 4.000 & 5.00 & 6.00 \\
\hline
\end{tabular}

Table 2. Mean values obtained by LX-STPM

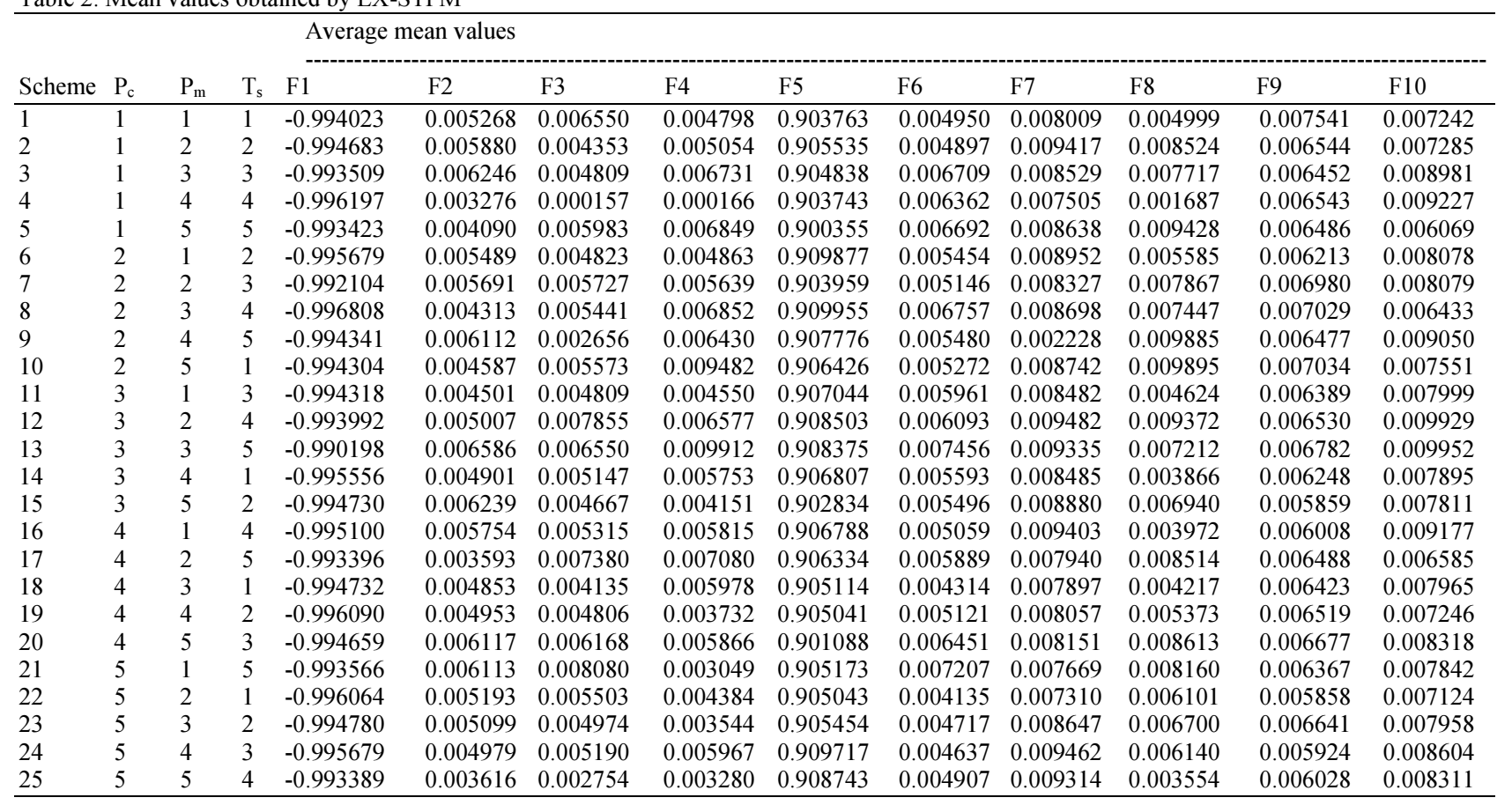

Table 3. Signal to noise ratio obtained by LX-STPM

\begin{tabular}{|c|c|c|c|c|c|c|c|}
\hline & Test problem & Parameter & Level 1 & Level 2 & Level 3 & Level 4 & Level 5 \\
\hline \multirow[t]{15}{*}{ Non -scalable } & \multirow[t]{3}{*}{ F1 } & $\mathrm{P}_{\mathrm{c}}$ & -46.987965 & -49.864596 & -42.913781 & -48.830912 & -49.007249 \\
\hline & & $\mathrm{P}_{\mathrm{m}}$ & -49.699353 & -48.867468 & -51.107116 & -50.920979 & -44.009586 \\
\hline & & $\mathrm{T}_{\mathrm{s}}$ & -50.108616 & -51.047973 & -43.973542 & -48.957491 & -52.516882 \\
\hline & \multirow[t]{3}{*}{$\mathrm{F} 2$} & $P_{c}$ & -1.743555 & -1.282400 & -1.490166 & -2.332524 & -1.877594 \\
\hline & & $\mathrm{P}_{\mathrm{m}}$ & -3.103375 & -2.013250 & -3.033788 & -1.048213 & -2.390707 \\
\hline & & $T_{s}$ & -2.346130 & -0.730407 & -1.864926 & -1.395280 & -3.568819 \\
\hline & \multirow[t]{3}{*}{ F3 } & $P_{c}$ & -6.153377 & -3.635323 & -7.394981 & -6.286327 & -2.157193 \\
\hline & & $\mathrm{P}_{\mathrm{m}}$ & -8.622772 & -7.137315 & -2.621246 & -3.607657 & -3.638211 \\
\hline & & $\mathrm{T}_{\mathrm{s}}$ & -6.295326 & -5.059373 & -2.925043 & -1.755747 & -9.591713 \\
\hline & \multirow[t]{3}{*}{ F4 } & $P_{c}$ & -7.775191 & 2.286348 & -2.693537 & -2.572654 & -10.462094 \\
\hline & & $\mathrm{P}_{\mathrm{m}}$ & -6.638635 & -6.045340 & -5.311474 & -2.433197 & -0.657120 \\
\hline & & $\mathrm{T}_{\mathrm{s}}$ & -2.424657 & -1.393622 & -4.209727 & -8.500844 & -6.277754 \\
\hline & \multirow[t]{3}{*}{ F5 } & $P_{c}$ & -53.131642 & -46.598672 & -52.310480 & -47.603402 & -62.640286 \\
\hline & & $\mathrm{P}_{\mathrm{m}}$ & -57.553688 & -48.442196 & -61.224382 & -49.878390 & -47.177354 \\
\hline & & $\mathrm{T}_{\mathrm{s}}$ & -48.652685 & -42.681904 & -54.720160 & -54.646598 & -54.468060 \\
\hline \multirow[t]{15}{*}{ Scalable } & \multirow[t]{3}{*}{ F6 } & $\mathrm{P}_{\mathrm{c}}$ & -2.976868 & -1.658867 & -0.624676 & -2.143402 & -4.074243 \\
\hline & & $\mathrm{P}_{\mathrm{m}}$ & -2.978965 & -3.199384 & -0.905250 & -1.317324 & -3.077133 \\
\hline & & $\mathrm{T}_{\mathrm{s}}$ & -4.564492 & -1.402520 & -2.071026 & -2.291031 & -1.148988 \\
\hline & \multirow[t]{3}{*}{ F7 } & $P_{c}$ & -12.140960 & -21.314548 & -9.167624 & -11.051592 & -13.462970 \\
\hline & & $P_{m}$ & -11.744038 & -8.683044 & -16.181969 & -16.247976 & -14.280667 \\
\hline & & $\mathrm{T}_{\mathrm{s}}$ & -18.987002 & -13.833990 & -12.131994 & -10.663811 & -11.520898 \\
\hline & \multirow[t]{3}{*}{ F8 } & $P_{c}$ & -9.505821 & -8.621828 & -3.589660 & -10.180009 & -5.276494 \\
\hline & & $\mathrm{P}_{\mathrm{m}}$ & -8.714793 & -0.354457 & -7.076247 & -11.392927 & -6.956863 \\
\hline & & $\mathrm{T}_{\mathrm{s}}$ & -14.734273 & -4.373476 & -5.021628 & -9.888543 & -1.321598 \\
\hline & \multirow[t]{3}{*}{ F9 } & $P_{c}$ & -7.413730 & -7.004289 & -7.196643 & -7.799782 & -8.045037 \\
\hline & & $\mathrm{P}_{\mathrm{m}}$ & -7.502007 & -7.916302 & -7.062529 & -7.457125 & -7.523324 \\
\hline & & $\mathrm{T}_{\mathrm{s}}$ & -7.475261 & -7.662214 & -7.702705 & -6.795770 & -7.823532 \\
\hline & \multirow[t]{3}{*}{ F10 } & $P_{c}$ & -10.927652 & -25.340856 & -9.597425 & -10.046173 & -10.503299 \\
\hline & & $\mathrm{P}_{\mathrm{m}}$ & -10.575697 & -9.547562 & -18.901763 & -13.625475 & -14.257714 \\
\hline & & $\mathrm{T}_{\mathrm{s}}$ & -9.223313 & -20.056886 & -11.537458 & -8.817122 & -16.780627 \\
\hline
\end{tabular}


Siew Mooi Lim et al. / Journal of Computer Science 2015, 11 (11): 1025.1031 DOI: $10.3844 /$ jessp.2015.1025.1031

Table 4. Ideal parameter values obtained by LX-STPM

\begin{tabular}{|c|c|c|c|c|}
\hline & Test problems & $P_{c}$ & $\mathrm{P}_{\mathrm{m}}$ & $\mathrm{T}_{\mathrm{s}}$ \\
\hline \multirow[t]{5}{*}{ Non-scalable test problems } & F1 & 0.70 & 0.020 & 4 \\
\hline & F2 & 0.65 & 0.010 & 3 \\
\hline & F3 & 0.80 & 0.006 & 5 \\
\hline & F4 & 0.65 & 0.020 & 3 \\
\hline & F5 & 0.65 & 0.020 & 3 \\
\hline \multirow[t]{5}{*}{ Scalable test problems } & F6 & 0.70 & 0.006 & 6 \\
\hline & F7 & 0.70 & 0.003 & 5 \\
\hline & F8 & 0.70 & 0.003 & 6 \\
\hline & F9 & 0.65 & 0.006 & 5 \\
\hline & F10 & 0.70 & 0.003 & 5 \\
\hline
\end{tabular}

Table 5. Final parameter settings for the comparative mutators

\begin{tabular}{|c|c|c|c|c|c|c|}
\hline \multirow[b]{2}{*}{ GA name } & \multicolumn{3}{|c|}{ Nonscalable } & \multicolumn{3}{|c|}{ Scalable } \\
\hline & $\mathrm{P}_{\mathrm{c}}$ & $\mathrm{P}_{\mathrm{m}}$ & $\mathrm{T}_{\mathrm{s}}$ & $\mathrm{P}_{\mathrm{c}}$ & $\mathrm{P}_{\mathrm{m}}$ & $\mathrm{T}_{\mathrm{s}}$ \\
\hline LX-STPM & 0.65 & 0.02 & 3 & 0.70 & 0.003 & 5 \\
\hline LX-LLM * & 0.70 & 0.02 & 3 & 0.60 & 0.008 & 3 \\
\hline
\end{tabular}

*(Deep and Katiyar, 2012)

Table 6. Mean values obtained by RX-STPM

\begin{tabular}{|c|c|c|c|c|c|c|c|c|c|c|c|c|c|}
\hline \multirow[b]{2}{*}{ Scheme } & \multirow[b]{2}{*}{$\mathrm{P}_{\mathrm{c}}$} & \multirow[b]{2}{*}{$\mathrm{P}_{\mathrm{m}}$} & \multirow[b]{2}{*}{$\mathrm{T}_{\mathrm{s}}$} & \multicolumn{10}{|c|}{ Average mean values } \\
\hline & & & & $\mathrm{F} 1$ & $\mathrm{~F} 2$ & F3 & $\mathrm{F} 4$ & F5 & F6 & F7 & F8 & F9 & F10 \\
\hline 1 & 1 & 1 & 1 & -0.993909 & 0.00454 & 0.005852 & 0.003942 & 0.90669 & 0.005688 & 0.006127 & 0.007899 & 0.005726 & 0.006448 \\
\hline 2 & 1 & 2 & 2 & -0.996181 & 0.002591 & 0.005882 & 0.002684 & 0.906646 & 0.003853 & 0.008360 & 0.002224 & 0.005864 & 0.005017 \\
\hline 3 & 1 & 3 & 3 & -0.994062 & 0.001523 & 0.003560 & 0.006887 & 0.904538 & 0.008049 & 0.006466 & 0.002544 & 0.004456 & 0.006455 \\
\hline 4 & 1 & 4 & 4 & -0.994639 & 0.006515 & 0.001779 & 0.000370 & 0.903756 & 0.006364 & 0.005605 & 0.003558 & 0.007558 & 0.009427 \\
\hline 5 & 1 & 5 & 5 & -0.999634 & 0.005551 & 0.000856 & 0.005849 & 0.901247 & 0.006239 & 0.009456 & 0.009144 & 0.005676 & 0.006158 \\
\hline 6 & 2 & 1 & 2 & -0.991407 & 0.002444 & 0.005775 & 0.005963 & 0.909870 & 0.004791 & 0.006942 & 0.005669 & 0.009059 & 0.008049 \\
\hline 7 & 2 & 2 & 3 & -0.995028 & 0.008097 & 0.006855 & 0.003539 & 0.903358 & 0.005735 & 0.007485 & 0.004863 & 0.005924 & 0.008079 \\
\hline 8 & 2 & 3 & 4 & -0.996290 & 0.004413 & 0.004227 & 0.007885 & 0.908957 & 0.007552 & 0.005510 & 0.006847 & 0.006027 & 0.005437 \\
\hline 9 & 2 & 4 & 5 & -0.999605 & 0.009357 & 0.003669 & 0.006863 & 0.908746 & 0.003111 & 0.008408 & 0.008845 & 0.006027 & 0.009046 \\
\hline 10 & 2 & 5 & 1 & -0.992930 & 0.006073 & 0.004883 & 0.005773 & 0.903700 & 0.005083 & 0.007369 & 0.009856 & 0.007045 & 0.008160 \\
\hline 11 & 3 & 1 & 3 & -0.998272 & 0.004790 & 0.004966 & 0.004586 & 0.903665 & 0.007344 & 0.006296 & 0.005624 & 0.007000 & 0.007972 \\
\hline 12 & 3 & 2 & 4 & -0.998535 & 0.004399 & 0.005882 & 0.007576 & 0.908856 & 0.005396 & 0.006573 & 0.008376 & 0.008534 & 0.009929 \\
\hline 13 & 3 & 3 & 5 & -0.994752 & 0.005480 & 0.008997 & 0.006915 & 0.908474 & 0.004319 & 0.004940 & 0.009215 & 0.006881 & 0.009959 \\
\hline 14 & 3 & 4 & 1 & -0.994396 & 0.004920 & 0.008556 & 0.004341 & 0.905807 & 0.005015 & 0.005720 & 0.003698 & 0.005247 & 0.009156 \\
\hline 15 & 3 & 5 & 2 & -0.996385 & 0.007021 & 0.006999 & 0.007702 & 0.908634 & 0.007033 & 0.009883 & 0.003940 & 0.005780 & 0.004812 \\
\hline 16 & 4 & 1 & 4 & -0.998623 & 0.004702 & 0.007554 & 0.006949 & 0.908788 & 0.005589 & 0.004139 & 0.005472 & 0.008009 & 0.009159 \\
\hline 17 & 4 & 2 & 5 & -0.996237 & 0.003819 & 0.007355 & 0.003080 & 0.905934 & 0.009369 & 0.005640 & 0.008690 & 0.006628 & 0.004884 \\
\hline 18 & 4 & 3 & 1 & -0.996102 & 0.006222 & 0.004146 & 0.004519 & 0.906691 & 0.005643 & 0.007896 & 0.004369 & 0.006483 & 0.008168 \\
\hline 19 & 4 & 4 & 2 & -0.993658 & 0.007392 & 0.004146 & 0.004734 & 0.905251 & 0.003852 & 0.008056 & 0.004573 & 0.005517 & 0.009266 \\
\hline 20 & 4 & 5 & 3 & -0.996626 & 0.005142 & 0.008998 & 0.009866 & 0.905888 & 0.005938 & 0.006773 & 0.008814 & 0.006257 & 0.005219 \\
\hline 21 & 5 & 1 & 5 & -0.996852 & 0.004357 & 0.008100 & 0.001079 & 0.901269 & 0.007049 & 0.008569 & 0.006809 & 0.006566 & 0.006850 \\
\hline 22 & 5 & 2 & 1 & -0.994688 & 0.003905 & 0.008903 & 0.005294 & 0.903658 & 0.005060 & 0.007410 & 0.004101 & 0.005959 & 0.008218 \\
\hline 23 & 5 & 3 & 2 & -0.998207 & 0.003796 & 0.004784 & 0.005625 & 0.909959 & 0.004053 & 0.009645 & 0.006884 & 0.006740 & 0.006778 \\
\hline 24 & 5 & 4 & 3 & -0.993068 & 0.000302 & 0.005885 & 0.005978 & 0.908995 & 0.005805 & 0.009563 & 0.005139 & 0.005901 & 0.006603 \\
\hline 25 & 5 & 5 & 4 & -0.997536 & 0.002654 & 0.002258 & 0.007283 & 0.902543 & 0.005191 & 0.007544 & 0.002588 & 0.007028 & 0.005318 \\
\hline
\end{tabular}

\section{Discussion}

\section{Final Parameter Settings for LX-STPM}

The proposed STPM is used with LX, which was adapted from past studies in order to form a new generational RCGA called LX-STPM. This section presents the analysis for finding the ideal parameter settings of $\mathrm{P}_{c}, \mathrm{P}_{\mathrm{m}}$ and $\mathrm{T}_{\mathrm{s}}$ values for LX-STPM. The search is done by using orthogonal arrays and $\mathrm{S} / \mathrm{N}$ ratio.

$\mathrm{S} / \mathrm{N}$ ratio experimental results for all the ten test problems are tabulated in Table 3 . The highlighted cell in each row has the greatest $\mathrm{S} / \mathrm{N}$ ratio, which represents the optimal level of the design factor. For example, for test problem F1, the optimal level are as follows: $\mathrm{P}_{\mathrm{c}}=$ level $3, \mathrm{P}_{\mathrm{m}}=$ level 5 and $\mathrm{T}_{\mathrm{s}}=$ level 3. As shown in Table 1 , the corresponding values for these three levels are $0.7,0.02$ and 4 respectively. It was observed that none of the test problems has any optimal value of design factor, which falls under Level 1. This indicates that minimum values for the optimal level of the design factor for $\mathrm{P}_{\mathrm{c}}, \mathrm{P}_{\mathrm{m}}$ and $\mathrm{T}_{\mathrm{s}}$ are at least $0.65,0.003$ and 3 respectively.

On the other hand, Table 4 summarizes the condition of probability values for the operators and the tournament sizes for all the ten test problems with the express purpose of keeping the algorithm stable. The $\mathrm{P}_{\mathrm{c}}$ values for all the ten test problems are either 0.65 or 0.70 except for F3, which settles at 0.80 . There is a 
big difference in the $\mathrm{P}_{\mathrm{m}}$ values for the category of non-scalable and scalable test problems. Majority of the non-scalable test problems have significantly higher $\mathrm{P}_{\mathrm{m}}$ values as compared to scalable test problems, except F3. The $T_{s}$ values for all nonscalable test problems are 3, except for F1 and F3 which settle at 4 and 5 respectively. The $\mathrm{T}_{\mathrm{s}}$ values for all scalable test problems are either 5 or 6 which are slightly higher than non-scalable test problems.

\section{Final Parameter Settings for RX-STPM}

STPM is reported as a more reliable, efficient and accurate mutator as compared to Log Logistic Mutation (LLM) (Lim et al., 2014a). Therefore, to analyze the effect of our newly proposed RX on the GA performance, RX is used with STPM to form a new generational Real Coded Genetic Algorithm (RCGA) called RX-STPM.
Table 7 indicates the $\mathrm{S} / \mathrm{N}$ ratio of the experimental results for all the ten test problems. The highlighted section in each row contains the greatest $\mathrm{S} / \mathrm{N}$ ratio, which denotes the optimal level of the design factor.

It was observed that none of the test problems has any optimal value of design factor that falls in Level 5, which means the maximum values for the optimal level of the design factor for $\mathrm{P}_{\mathrm{c}}, \mathrm{P}_{\mathrm{m}}$ and $\mathrm{T}_{\mathrm{s}}$ are less than 0.80 , 0.02 and 6 respectively.

Table 8 summarizes the ideal values of $\mathrm{P}_{c}, \mathrm{P}_{\mathrm{m}}$ and $\mathrm{T}_{\mathrm{s}}$ for all the ten test problems. It is evident that the final values of $T_{s}$ are the same for both non-scalable and scalable problems. Apart from that, there is not much difference in the final values of $P_{c}$ for nonscalable and scalable problems. Interestingly, the final values of $\mathrm{P}_{\mathrm{m}}$ indicate a huge difference between nonscalable and scalable problems whereby three of the non-scalable test problems (problem 2, 3 and 5) have significantly higher $\mathrm{P}_{\mathrm{m}}$ values.

Table 7. Signal to noise ratio obtained by RX-STPM

\begin{tabular}{|c|c|c|c|c|c|c|c|}
\hline & Test problem & Parameter & Level 1 & Level 2 & Level 3 & Level 4 & Level 5 \\
\hline \multirow[t]{15}{*}{ Non -scalable } & \multirow[t]{3}{*}{ F1 } & $\mathrm{P}_{\mathrm{c}}$ & -39.505648 & -50.265472 & -55.723947 & -46.991324 & -46.912784 \\
\hline & & $\mathrm{P}_{\mathrm{m}}$ & -48.238897 & -53.135684 & -41.133821 & -46.988705 & -49.902069 \\
\hline & & $\mathrm{T}_{\mathrm{s}}$ & -48.549656 & -48.545303 & -39.832507 & -46.011948 & -56.459762 \\
\hline & \multirow[t]{3}{*}{ F2 } & $\mathrm{P}_{\mathrm{c}}$ & -0.064194 & -3.811003 & 0.835779 & 0.159147 & 0.226931 \\
\hline & & $\mathrm{P}_{\mathrm{m}}$ & 0.602073 & -4.556569 & -1.222790 & 4.591543 & -2.966072 \\
\hline & & $\mathrm{T}_{\mathrm{s}}$ & 2.121291 & -2.457554 & 0.179020 & -0.350718 & -2.202683 \\
\hline & \multirow[t]{3}{*}{ F3 } & $\mathrm{P}_{\mathrm{c}}$ & -4.622708 & -3.496788 & -2.704636 & -10.113749 & -7.448059 \\
\hline & & $\mathrm{P}_{\mathrm{m}}$ & -8.872113 & -8.911837 & -4.139311 & -2.842856 & -3.619823 \\
\hline & & $\mathrm{T}_{\mathrm{s}}$ & -3.684603 & -7.856145 & -5.716134 & -3.935402 & -7.193657 \\
\hline & \multirow[t]{3}{*}{$\mathrm{F} 4$} & $\mathrm{P}_{\mathrm{c}}$ & 1.206233 & -7.818810 & -4.426664 & -4.521652 & -0.172815 \\
\hline & & $\mathrm{P}_{\mathrm{m}}$ & -1.441374 & -0.023079 & 2.119994 & -8.060425 & -9.592108 \\
\hline & & $\mathrm{T}_{\mathrm{s}}$ & 4.371242 & -5.857433 & -1.822926 & -5.225017 & -6.572109 \\
\hline & \multirow[t]{3}{*}{ F5 } & $\mathrm{P}_{\mathrm{c}}$ & -53.750282 & -61.874985 & -43.978204 & -46.558810 & -52.803793 \\
\hline & & $\mathrm{P}_{\mathrm{m}}$ & -56.458928 & -48.079727 & -50.551505 & -45.608499 & -61.770409 \\
\hline & & $\mathrm{T}_{\mathrm{s}}$ & -43.091500 & -54.268834 & -46.933642 & -55.136386 & -54.700521 \\
\hline \multirow[t]{15}{*}{ Scalable } & \multirow[t]{3}{*}{ F6 } & $\mathrm{P}_{\mathrm{c}}$ & -1.640927 & -0.843169 & 0.174223 & -1.302569 & -2.511044 \\
\hline & & $P_{m}$ & -2.132311 & 0.048578 & 1.288086 & -2.229758 & -3.098082 \\
\hline & & $\mathrm{T}_{\mathrm{s}}$ & 2.974610 & -1.379344 & -2.738437 & -1.433658 & -3.546657 \\
\hline & \multirow[t]{3}{*}{ F7 } & $\mathrm{P}_{\mathrm{c}}^{\mathrm{s}}$ & -6.909073 & -10.805980 & -11.752055 & -7.264409 & -12.489357 \\
\hline & & $P_{m}$ & -8.158061 & -11.588905 & -8.074444 & -9.727442 & -11.672022 \\
\hline & & $\mathrm{T}_{\mathrm{s}}$ & -9.056043 & -12.803067 & -4.137446 & -12.296723 & -10.927595 \\
\hline & \multirow[t]{3}{*}{ F8 } & $\mathrm{P}_{\mathrm{c}}$ & -2.735408 & -4.054247 & -6.351887 & -3.580946 & -6.601620 \\
\hline & & $P_{m}$ & -6.016248 & 1.006936 & -6.925244 & -9.313932 & -2.075621 \\
\hline & & $\mathrm{T}_{\mathrm{s}}$ & 0.315914 & -2.701934 & -4.456797 & -6.855876 & -9.625415 \\
\hline & \multirow[t]{3}{*}{ F9 } & $\mathrm{P}_{\mathrm{c}}$ & -7.748323 & -8.225013 & -6.158830 & -7.957079 & -7.555669 \\
\hline & & $\mathrm{P}_{\mathrm{m}}$ & -8.961132 & -6.115528 & -8.981577 & -6.720876 & -6.865801 \\
\hline & & & -6.560887 & -7.325642 & -7.456554 & -9.167046 & -7.134784 \\
\hline & \multirow[t]{3}{*}{ F10 } & $\mathrm{P}_{\mathrm{c}}$ & -6.032095 & -7.974748 & -15.267805 & -6.974514 & -7.698748 \\
\hline & & $\mathrm{P}_{\mathrm{m}}$ & -11.867713 & -3.167821 & -10.236845 & -10.482752 & -8.192780 \\
\hline & & $\mathrm{T}_{\mathrm{s}}$ & -6.800971 & -7.051732 & -10.873279 & -8.100093 & -11.121835 \\
\hline
\end{tabular}

Table 8 . Ideal parameter values obtained by RX-STPM

\begin{tabular}{lllll}
\hline & Test problems & $\mathrm{P}_{\mathrm{c}}$ & $\mathrm{P}_{\mathrm{m}}$ & $\mathrm{T}_{\mathrm{s}}$ \\
\hline Non-scalable test problems & $\mathrm{F} 1$ & 0.60 & 0.006 & 0.010 \\
& $\mathrm{~F} 2$ & 0.70 & 0.010 & 2 \\
& $\mathrm{~F} 3$ & 0.70 & 0.006 & 0.010 \\
Scalable test problems & $\mathrm{F} 4$ & 0.60 & 0.006 & 2 \\
& $\mathrm{~F} 5$ & 0.70 & 0.006 & 2 \\
& $\mathrm{~F} 6$ & 0.70 & 0.006 & 4 \\
& $\mathrm{~F} 7$ & 0.60 & 0.003 & 2 \\
& $\mathrm{~F} 8$ & 0.60 & 0.003 & 2 \\
& $\mathrm{~F} 9$ & 0.70 & 0.003 & 2 \\
\hline
\end{tabular}


Table 9. Final parameter settings for the comparative crossovers

\begin{tabular}{|c|c|c|c|c|c|c|}
\hline \multirow[b]{2}{*}{ GA name } & \multicolumn{3}{|c|}{ Non-scalable } & \multicolumn{3}{|c|}{ Scalable } \\
\hline & $\mathrm{P}_{\mathrm{c}}$ & $\mathrm{P}_{\mathrm{m}}$ & $\mathrm{T}_{\mathrm{s}}$ & $\mathrm{P}_{\mathrm{c}}$ & $\mathrm{P}_{\mathrm{m}}$ & $\mathrm{T}_{\mathrm{s}}$ \\
\hline RX-STPM & 0.70 & 0.01 & 2 & 0.60 & 0.003 & 2 \\
\hline LX-STPM & 0.65 & 0.02 & 3 & 0.70 & 0.003 & 5 \\
\hline
\end{tabular}

\section{Conclusion}

It is worth mentioning that the final parameter settings for LX-STPM and RX-STPM as presented in Table 5 and 9 are suggested in accordance with the positive results gathered for the majority of the problems.However, the parameters of these findings may not necessary be generalized for other context of problems.This type of experiment falls under the category of parameter tuning approach whereby all the parameter values are kept fixed during an evolution process.GA parameter settings are algorithm and problem-dependent. That aside, there are no GA tools which could generalize the adjustment of control parameter either. As reported in (Sarmady, 2007), there has been no general conclusion drawn in relation to the optimum GA parameterization. So, researchers are to design their ideal operators, parameters and mechanisms to tackle the problems. It was also observable in the experimental results from LX-STPM and RX-STPM whereby the final parameter values are different for both algorithms. Future studies can look into many aspects to improve the GA parameter settings such as to incorporate parameter-control approach which enables the GA to modify its own parameters dynamically during the search to provide optimal solutions.

\section{Acknowledgment}

The authors wish to thank anonymous reviewers for their valuable, detailed comments that improve both the content and representation of this study.

\section{Author's Contributions}

Siew Mooi Lim: Participated in all experiments, coordinated the data-analysis and contributed to the writing of the manuscript.

Md. Nasir Sulaiman: $\mathrm{He}$ is the main research supervisor. He organized the study and suggested the objectives and major contributions of the research.

Norwati Mustapha: Contributed in writing and organized the structure of the research.

Abu Bakar Md. Sultan: Contributed in technical aspects of genetic algorithm issues of the research.

\section{Ethics}

The corresponding author confirms that the other authors have read and approved the manuscript and there is no ethical issue involved. This paper is original and contains unpublished material.

\section{References}

Abhang, L. and M. Hameedullah, 2012. Optimization of machining parameters in steel turning operation by taguchi method. Procedia Eng., 38: 40-48. DOI: $10.1016 /$ j.proeng.2012.06.007

Çakıroğlu, R. and A. Acır, 2013. Optimization of cutting parameters on drill bit temperature in drilling by Taguchi method. Measurement, 46: 3525-3531. DOI: 10.1016/j.measurement.2013.06.046

Camposeco-Negrete, C., 2013. Optimization of cutting parameters for minimizing energy consumption in turning of AISI 6061 T6 using Taguchi methodology and ANOVA. J. Cleaner Product., 53: 195-203. DOI: 10.1016/j.jclepro.2013.03.049

Davim, J.P., 2003. Design of optimisation of cutting parameters for turning metal matrix composites based on the orthogonal arrays. J. Mater. Processing Technol., 132: 340-344. DOI: 10.1016/S0924-0136(02)00946-9

De Jong, K., 2007. Parameter setting in EAs: A 30 year perspective. Parameter Setting Evolutionary Algorithms, 54: 1-18. DOI: $10.1007 / 978-3-540-69432-8$ _ 1

Deep, K. and V. Katiyar, 2012. A new real coded genetic algorithm operator: Log logistic mutation. Proceedings of the International Conference on Soft Computing for Problem Solving, Dec. 20-22, pp: 193-200. DOI: 10.1007/978-81-322-0487-9_19

Fraley, S., M. Oom, B. Terrien and J. Date, 2006. Design of experiments via Taguchi methods: Orthogonal arrays. USA.

Hou, T., C. Su and W. Liu, 2007. Parameters optimization of a nano-particle wet milling process using the Taguchi method, response surface method and genetic algorithm. Powder Technol., 173: 153-162. DOI: 10.1016/j.powtec.2006.11.019

Hsieh, C., J. Chou and Y. Wu, 2001. Optimal grey-fuzzy gain-scheduler design using Taguchi-HGA method. J. Intelligent Robotic Syst., 32: 321-345. DOI: 10.1023/A:1013911905035

Lim, S.M., M.N. Sulaiman, A.B. Sultan, N. Mustapha and B.A. Tejo, 2014a. Real Coded Genetic Algorithm (RCGA): A new RCGA mutator called scale truncated pare to mutation. J. Theoretical Applied Inf. Technol., 60: 245-253. 
Lim, S.M., M.N. Sulaiman, A.B. Sultan, N. Mustapha and B.A. Tejo, 2014b. A new real coded genetic algorithm crossover: Rayleigh crossover. J. Theoretical Applied Inf. Technol., 62: 262-268.

Lim, S.M., M.N. Sulaiman, A.B. Sultan, N. Mustapha and B.A. Tejo, 2015a. New real coded genetic algorithm operators for minimization of molecular potential energy function. Applied Artificial Intellig., 29: 979-991.

Lim, S.M., M.N. Sulaiman, N. Mustapha and A.B. Sultan, 2015b. New crossover and mutation operators of real coded genetic algorithms for optimization of molecular structures. Annals of Mathematics and Artificial Intelligence.

Lim, S.M., M.N. Sulaiman, N. Mustapha and A.B. Sultan 2015c. Metaheuristic techniques for conformational search. International Research Journal of Engineering and Technology.

Liu, D. and Y. Cai, 2005. Taguchi method for solving the economic dispatch problem with nonsmooth cost functions. Power Syst. IEEE Trans., 20: 2006-2014. DOI: 10.1109/TPWRS.2005.857939
Montgomery, D.C., 2008. Design and Analysis of Experiments. 7th Edn., John Wiley and Sons, Hoboken, ISBN-10: 0470128666, pp: 680.

Sarmady, S., 2007. An investigation on genetic algorithm parameters. School Comput. Sci.

Subbaraj, P., R. Rengaraj and S. Salivahanan, 2011. Enhancement of self-adaptive real-coded genetic algorithm using Taguchi method for Economic dispatch problem. Applied Soft Computing, 11: 83-92. DOI: $10.1016 /$ j.asoc.2009.10.019

Tsai, J., T. Liu and J. Chou, 2004. Hybrid taguchigenetic algorithm for global numerical optimization. Evolutionary Comput. IEEE Trans., 8: 365-377. DOI: 10.1109/TEVC.2004.826895

Younes, M. and M. Rahli, 2006. On the choice genetic parameters with Taguchi method applied in economic power dispatch. Leonardo J. Sci., 9: 9-24. 